\title{
Techniques to Investigate Neuronal Mitochondrial Function and its Pharmacological Modulation
}

\author{
Jorge M. A. Oliveira*1,2 \\ ${ }^{I}$ REQUIMTE, Department of Drug Sciences, Faculty of Pharmacy, University of Porto, \\ Portugal; \\ ${ }^{2}$ Mitochondrial Research Group, Institute for Ageing and Health, Medical School, Newcastle \\ University, $U K$
}

*Corresponding author at Faculdade de Farmácia da Universidade do Porto, Rua Aníbal Cunha, 164, 4050-047 Porto, Portugal.

E-mail: jorgemao@ff.up.pt

Keywords: mitochondria, neurons, respiration, membrane potential, calcium, biogenesis, mitochondrial dynamics, live imaging

\begin{abstract}
Mitochondria are central regulators of neuronal homeostasis and survival, and increasingly viewed as a drug target in several acute and chronic neurological disorders, e.g. stroke, Alzheimer's, Parkinson's, and Huntington's diseases. Frequent working hypotheses aim to establish whether and how chemical or genetic lesions affect mitochondrial function in neurons, and whether this can be rescued by pharmacological treatments. However, the generic designation 'mitochondrial function' actually encompasses a wide spectrum of individual activities, too numerous to be fully quantified by any single available technique. This review aims to provide a broad perspective on the roles played by neuronal mitochondria, and addresses multiple techniques that can be used to derive instructive functional indicators. These include measurements of mitochondrial respiration, ATP production, membrane potential, calcium handling, biogenesis, dynamic movement as well as fusion and fission. Technique descriptions are preceded by a summary of mitochondrial physiology and pharmacological tools required for functional modulation and parameter determination. Hopefully, these will assist researchers interested in testing mitochondria as a drug target in neurological disease models.
\end{abstract}

\section{Introduction}

\subsection{Neuronal mitochondria: a vital and dynamic asset}

Neurons are highly specialized and polarized cells with large energy requirements. Excitability demands a continuous maintenance of steep ion gradients, which consumes vast amounts of ATP primarily provided by oxidative phosphorylation, thus rendering neurons critically dependent on mitochondria and continuous oxygen supply [1]. Mitochondria assist neurotransmission and synaptic plasticity via multiple roles beyond ATP production. They regulate spatiotemporal patterns of intracellular calcium $\left(\left[\mathrm{Ca}^{2+}\right]_{i}\right)$ signalling $[2]$ and move purposefully to meet variable demands across neuronal soma, axons, dendrites and synaptic sites [3]. Throughout the lifespan of their post-mitotic hosts, neuronal mitochondria 
continuously regenerate through a biogenesis process assisted by nuclear and mitochondrial gene products [4]. Moreover, mitochondria undergo fission and fusion cycles that modulate their number, size and content, allowing functional segregation and adaptation to different neuronal compartments and microenvironments [5,6], and likely assist mitochondrial quality control mechanisms [7]. Furthermore, mitochondria govern reactive oxygen species (ROS) formation and signalling, assist steroid and heme biosynthesis, and several other metabolic pathways, being also central regulators of apoptosis and neuronal survival [8]. Interestingly, recent evidence suggest that all extant eukaryotes possess mitochondria, some in the form of reduced homologues, e.g. hydrogenosomes and mitosomes. So far, the single common metabolic function identified across all homologues is iron-sulfur cluster assembly, clearly one of the most fundamental mitochondrial functions $[9,10]$. Focusing on humans, the frequent neurological phenotype linked to mitochondria gene mutations [11], and the association of mitochondrial dysfunction with acute and chronic neurological disorders $[12,13]$, strongly emphasize how much neuronal health depends on fully functional mitochondria, and why these are targets for neuroprotection.

\subsection{The value of representative functional indicators}

When investigating neuronal mitochondria under (patho)-physiological conditions or pharmacological interventions one should consider representative functional indicators. Indeed, from the experimental standpoint, comprehensively quantifying the full spectrum of mitochondrial activities while searching for dysfunctions is tantamount to impossible. Hopefully, scientific progress will prove the previous sentence wrong. A Pubmed search (www.ncbi.nlm.nih.gov/pubmed) for "mitochondrial function" OR "mitochondrial dysfunction" AND "neurons" yields over 1,000 publications during the last decade, exceeding 7,000 if searching without "neurons". Indeed, two frequent working hypothesis in neuroscience and others fields are: $(i)$ disease $x$ affects mitochondrial function; and (ii) drug $y$ induces/improves mitochondrial dysfunction. In some cases, sequencing the mitochondrial genome or nuclear-encoded mitochondrial genes objectively answers the first hypothesis, e.g. by finding loss-of-function mutations in critical genes. In others cases, mutations may be found but it will remain unknown whether these have functional consequences. Still, in most cases where the first, and particularly, the second hypothesis are formulated, one must rely on functional indicators. Thus, it becomes critical to consider: $(i)$ which functional indicators; $(i i)$ what do they mean; and (iii) how are they quantified. The present review addresses these issues in the context of neuronal mitochondria.

The next section summarizes mitochondria physiological and pharmacological principles, related to subsequently described techniques. Hopefully, these will provide the grounds for those interested in testing mitochondria as a drug target in neurological disease models.

\section{Mitochondrial physiology and pharmacology}

\subsection{Respiratory chain, proton motive force, ATP synthesis, and proton leaks}

Mitochondria exhibit a core matrix surrounded by two membranes, the inner one containing the respiratory chain (Figure 1,A). This chain combines the sequential activity of enzyme complexes, namely complex I (NADH-ubiquinone oxidoreductase), II (succinate-ubiquinone oxidoreductase), III (ubiquinol-cytochrome $c$ oxidoreductase), and IV (cytochrome $c$ oxidase). Significantly, complex II contains succinate dehydrogenase, a nuclear-encoded Krebs cycle enzyme. Electrons from NADH or $\mathrm{FADH}_{2}$ enter the chain at Complex I or II, respectively, being sequentially shuttled down their electrochemical potential to complex III (via ubiquinone, a.k.a. coenzyme $\mathrm{Q}_{10}$ ), and then IV (via cytochrome $c$ ) where $\mathrm{O}_{2}$ is consumed 
as the final electron acceptor. This electron flux drives proton $\left(\mathrm{H}^{+}\right)$efflux towards the intermembrane space via $\mathrm{H}^{+}$pumps in complex I, III and IV, generating an electrochemical $\mathrm{H}^{+}$gradient $\left(\Delta \mu_{\mathrm{H}+}\right)$ expressed in electrical potential units $(\mathrm{mV})$ as the proton motive force $(\Delta p)$. At $37^{\circ} \mathrm{C}, \Delta \mathrm{p}=\Delta \psi_{\mathrm{m}}-60 \Delta \mathrm{pH}$ (where $\Delta \psi_{\mathrm{m}}$ is the mitochondrial membrane potential, and $\Delta \mathrm{pH}$ the $\mathrm{H}^{+}$gradient). $\Delta \mathrm{p}$ is the primary bioenergetic parameter controlling mitochondrial ATP synthesis, while $\Delta \psi_{\mathrm{m}}$ regulates mitochondrial $\mathrm{Ca}^{2+}$ uptake and ROS generation. Under most conditions $\Delta \psi_{\mathrm{m}}$ is the dominant component $(\sim 80 \%)$ of $\Delta \mathrm{p}$. Thus, $\Delta \psi_{\mathrm{m}}$ and $\Delta \mathrm{p}$ are often used interchangeably when referring to the common driving force for key mitochondria functions $[14,15]$.

ATP synthase (complex $\mathrm{V}$ or $\mathrm{F}_{0} \mathrm{~F}_{1}$ ATPase) closes the proton circuit established by respiratory chain activity. In analogy to hydroelectric dams accumulating upstream water and channelling it through turbines, mitochondria accumulate protons in the intermembrane space and channel them through ATP synthase generating ATP, which is exported to the cytosol via the adenine nucleotide translocase (ANT). Meaningfully, mitochondria may reverse ATP synthase, consuming rather than generating ATP. While transient ATP synthase reversal allows $\Delta \mathrm{p}$ maintenance, crucial for mitochondrial activity, unrestrained reversal may lead to cellular ATP depletion [16].

$\mathrm{H}^{+}$leaks across the inner mitochondrial membrane decrease the coupling efficiency between $\mathrm{O}_{2}$ consumption and ATP synthesis. This 'uncoupling' plays a physiological role in limiting $\Delta \mathrm{p}$, otherwise increasing electrons dwell time in complex I and III where they leak into oxygen forming superoxide, which in excess may have deleterious effects [17]. Mitochondrial $\mathrm{H}^{+}$leaks include an inducible and a basal component, which is insensitive to known activators and inhibitors [18]. Inducible $\mathrm{H}^{+}$leaks involve uncoupling proteins (e.g. $\mathrm{UCP} 1$; [19]) and the ANT fatty-acid-dependent $\mathrm{H}^{+}$leak. Basal $\mathrm{H}^{+}$leaks may occur at the ANT-phospholipid interface, since they increase with ANT content but are independent from known ANT functions [20].

\subsection{Mitochondrial calcium handling in neurons}

Mitochondria are central to neuronal $\mathrm{Ca}^{2+}$ homeostasis (Figure 1, right). In addition to energizing non-mitochondrial $\mathrm{Ca}^{2+}$-handling mechanisms, e.g. plasmalemmal and endoplasmic reticulum (ER) $\mathrm{Ca}^{2+}$-ATPases, mitochondria are $\left[\mathrm{Ca}^{2+}\right]_{\mathrm{i}}$ modulators and high capacity $\mathrm{Ca}^{2+}$ storage systems. The latter being particularly relevant in neurons, excitable cells capable of sudden and extensive $\left[\mathrm{Ca}^{2+}\right]_{\mathrm{i}}$ increases, where mitochondria $\mathrm{Ca}^{2+}$ sequestration prevents cytosolic $\mathrm{Ca}^{2+}$ overload and shapes feedback inhibition of $\mathrm{Ca}^{2+}$ transients $[1,21]$. Mitochondria regulate $\left[\mathrm{Ca}^{2+}\right]_{\mathrm{i}}$ via uptake and release, controlling cytoplasmic $\mathrm{Ca}^{2+}$ microdomains, and shaping frequency/propagation of $\mathrm{Ca}^{2+}$ signals. The regulation is reciprocal since mitochondrial $\mathrm{Ca}^{2+}$ uptake plays key metabolic roles, tuning substrate uptake, Krebs cycle activity and ATP synthesis, and influences mitochondrial motility and morphology [22,23]. Mitochondria start accumulating $\mathrm{Ca}^{2+}$ when the neighbouring concentration rises above the set point $(\sim 0.5 \mu \mathrm{M})$ at which uptake is balanced by efflux [24]. The mitochondrial $\mathrm{Ca}^{2+}$ uniporter and the $\mathrm{Na}^{+} / \mathrm{Ca}^{2+}(3: 1)$ exchanger provide the main matrix $\mathrm{Ca}^{2+}$ uptake and efflux pathways, respectively $[25,26]$. Above the set point, increasing uniporter activity drives $\mathrm{Ca}^{2+}$ to the matrix where buffering occurs via $\mathrm{Ca}^{2+}$ phosphate complexes. These are reversible complexes, and when plasmalemmal $\mathrm{Ca}^{2+}$ pumps restore $\left[\mathrm{Ca}^{2+}\right]_{\mathrm{i}}$ below the set point, mitochondria gradually release $\mathrm{Ca}^{2+}$ back to the cytosol [27].

$\mathrm{Ca}^{2+}$ accumulation is driven by $\Delta \psi_{\mathrm{m}}$ in competition with ATP production. If oxidative phosphorylation decreases, glycolysis may increase via the Pasteur effect, albeit much less prominently in neurons than in glycogen containing cells. Upon ATP synthase reversal, $\mathrm{Ca}^{2+}$ accumulation may also be driven by glycolytic ATP hydrolysis. Still, mitochondria have a 
limited $\mathrm{Ca}^{2+}$ buffering capacity, and when exceeded it precipitates mitochondrial permeability transition (mPT). This consists of non-specific pore opening at the inner mitochondrial membrane, rendering it permeable to ions and molecules $<1.5 \mathrm{KDa}$. With the exception of transient pore openings, which may play physiological roles, unrestrained $\mathrm{mPT}$ has catastrophic consequences for mitochondria and their hosts. Thus, mPT is currently a subject of intense research in neuronal injury and a drug target in neuroprotection [28-30].

\subsection{Mitochondrial biogenesis and dynamics}

Biogenesis is critical to replenish mitochondria throughout neuronal lifespan (Figure 1, B). Damaged mitochondria are degraded by mitophagy (mitochondria autophagy), a controlled process preventing the release of apoptotic factors that might lead to neuronal death. In addition, biogenesis increases to meet metabolic demands or compensate for mitochondrial dysfunction [4,6,31]. Mitochondria possess their own DNA (mtDNA), each cell containing several thousand copies of these small circular genomes that hold testimony to a remarkable evolutionary background [32,33]. Nevertheless, the mitochondrial genome is now insufficient for independent replication. Moreover, only a few proteins are synthesized within mitochondria, which must import about 1,000 different nuclear-encoded proteins [34]. Thus, for mitochondria to proliferate, i.e., undergo biogenesis, a concerted action must take place between nuclear and mitochondrial genes. Several transcription factors play an important role in mitochondrial biogenesis, most notably, mitochondria transcription factor A (mtTFA), mitochondrial transcription specificity factors, nuclear respiratory factors (NRF-1 and NRF2 ), and peroxisome proliferator-activated receptor $\gamma$ coactivator-1 $\alpha$ (PGC-1 $\alpha$ ), the latter possibly exerting master regulatory roles [35]. Mitochondrial biogenesis may be altered in neurological disorders, thus being a putative therapeutic target [4].

Neuronal mitochondria are highly dynamic, undergoing fission, fusion and movement along neuronal processes (Figure 1, B,C). Fission-fusion cycles allow mixing and asymmetric segregation of mitochondrial contents, including mtDNA, which may compensate or propagate mutations. In addition to functional segregation, fission-fusion cycles regulate mitochondria number, size and morphology, whereas movement displaces mitochondria to sites in need, which in human motor neurons may exceed one meter distance. In combination, fission-fusion and movement ensure efficient management and distribution of limited mitochondrial resources across vast neuritic networks with variable spatiotemporal demands.

Mitochondrial fission and fusion are membrane-remodelling events assisted by evolutionarily conserved dynamin-related GTPases (Figure 1,B). Fission involves recruitment of cytosolic DRP-1 and membrane bound Fis-1, whereas fusion of the outer and inner membranes is assisted by mitofusins (Mfn-1 and Mfn-2) and optic atrophy-1 (OPA-1), respectively. Significantly, Mfn-2 mutation is linked to the peripheral neuropathy CharcotMarie-Tooth type 2A, OPA-1 mutation causes hereditary optic nerve degeneration and progressive blindness, and DRP-1 mutation has been associated with abnormal brain development [36,37].

Mitochondria use adaptor proteins to ride molecular motors, possibly paying an ATP fare to accelerate along cytoskeletal tracks (Figure 1,C). They use microtubules for long distance fast axonal transport, and shift to actin microfilaments for short distances in pre- and postsynaptic endings. Typically, kinesin motors drive mitochondria anterogradely, towards the $(+)$ end of microtubules in growth cones, whereas dynein motors mediate retrograde transport. Miro, Milton and syntabulin are adaptor proteins for kinesins, whereas dynactin adapts mitochondria to dyneins $[3,13,38]$. Miro is also a $\mathrm{Ca}^{2+}$ sensor mediating motility in low $\left[\mathrm{Ca}^{2+}\right]_{\mathrm{i}}$ environments and arresting mitochondria in high $\left[\mathrm{Ca}^{2+}\right]_{\mathrm{i}}$ sites in need of buffering such as active synapses [39,40]. Mitochondria also follow increasing ADP gradients, moving towards ATP impoverished sites [38]. Interestingly, molecular motors remain functional at 
relatively low $[\mathrm{ATP}]_{\mathrm{i}}$ sites [3], but inhibition of mitochondrial ATP synthesis with oligomycin arrested trafficking in forebrain [41] but not cerebellar neurons [42], which might be explained by differences in glycolytic ATP availability or $\left[\mathrm{Ca}^{2+}\right]_{\mathrm{i}}$ levels. Additional modulation of mitochondrial function is described below.

\subsection{Pharmacological modulation of mitochondrial function}

Several pharmacological tools assist the study of mitochondrial function. However, these are not widely applicable across different preparations and techniques. Useful tools in isolated mitochondria may not reach effective concentrations within intact cells, sometimes requiring microinjection or membrane permeabilization, e.g. with digitonin or saponin. Also, unpredicted/non-selective drug effects on extra-mitochondrial targets often complicate in situ data interpretation. On the other hand, useless drugs for isolated mitochondria experiments may be quite helpful in situ (e.g. modulation of trafficking and other dynamic properties).

\subsubsection{Respiratory Complexes and ATP Synthase Inhibitors}

In intact neurons, inhibition of any respiratory complex impairs the chain. Complex I inhibition limits $\mathrm{NAD}^{+}$availability, compromising succinate synthesis for alternative feeding of complex II. Conversely, complex II inhibition arrests the Krebs cycle, limiting complex I substrate [14]. Because complex III and IV act downstream of electron entry sites, their inhibition also halts the respiratory chain (Figure 1, $A$ ). Still, complex I-III inhibition can be elegantly bypassed in intact neurons by using TMPD (2,3,5,6-tetramethyl- $p$ phenylenediamine)/ascorbate, which donates electrons to complex IV, allowing $\mathrm{H}^{+}$extrusion and $\Delta p$ recovery [8]. To bypass complex I inhibition in intact neurons, one possibility is methyl-succinate, a cell-permeable analogue of a complex II substrate [43].

Complex I inhibitors are numerous, being chiefly represented by the semi-quinone antagonist rotenone and by $\mathrm{MPP}^{+}$, the toxic metabolite from 1-methyl-4-phenyl-1,2,3,6tetrahydropyridine commonly used to induce Parkinson-like neurodegeneration [44,45]. Complex II inhibitors primarily include the competitive malonate and the irreversible 3nitropropionic acid (3-NP), both acting on succinate dehydrogenase. Notably, 3-NP is frequently used to simulate Huntington's disease neurodegeneration [46]. Complex III is inhibited by myxothiazol and antimycin A, respectively, upstream and downstream to the ubisemiquinone site. Because at that site electrons can be transferred to oxygen, blocking downstream electron flow with antimycin A is a useful strategy to increase mitochondrial superoxide formation in neurons [47,48]. Complex $I V$ inhibitors like cyanide and azide inhibit electron transfer to oxygen, inducing chemical hypoxia in mechanistic studies of hypoxic neurodegeneration [49].

Mitochondrial ATP synthase contains a proton-translocating membrane-embedded domain $\left(\mathrm{F}_{0}\right)$, and a catalytic domain $\left(\mathrm{F}_{1}\right)$. Protons extruded by complex I, III and IV re-enter the matrix via $\mathrm{F}_{0}$ and energize a mechanical rotary mechanism linked to ATP synthesis via $\mathrm{F}_{1}$ (Figure 1,A). Numerous natural and synthetic compounds inhibit ATP synthase (for a comprehensive review see Ref. [50]). The macrolide oligomycin is commonly used in experiments with neurons. Direct ATP synthase inhibition can be achieved by blocking $\mathrm{F}_{0}$ proton-flux with oligomycin, thus preventing ATP synthesis/hydrolysis. In neurons, excess oligomycin may also inhibit plasmalemmal $\mathrm{Na}^{+} / \mathrm{K}^{+}$ATPase [51]. Oligomycin typically increases $\Delta \psi_{\mathrm{m}}$ (hyperpolarization; but see oligomycin null-point test in Section 4), and allows the study of other $\Delta \psi_{\mathrm{m}}$-related functions, e.g. $\mathrm{Ca}^{2+}$ buffering, ROS production, independently of ATP synthesis/hydrolysis. Cell survival in the presence of oligomycin will primarily depend on glycolytic capacity, which may vary significantly across neuronal types [14]. $F_{1}$ domain inhibition also directly arrests mitochondrial ATP synthase. The endogenous inhibitor protein $\mathrm{IF}_{1}$ may prevent ATP depletion when neuronal insults reverse ATP synthase [16]. 
Significantly, some mitochondrial markers like rhodamine-6G and structurally related lipophilic cations block the $F_{1}$ domain when in excess concentration, compromising interpretation of functional assays $[52,53]$. Indirect $\mathrm{F}_{0} \mathrm{~F}_{1}$ ATP synthase inhibition occurs upon mitochondrial uncoupling, namely by drugs decreasing the $\mathrm{H}^{+}$gradient required for ATP generation (e.g. protonophores; see below).

\subsubsection{Ionophores, Inhibitors of $\mathrm{mPT}, \mathrm{Ca}^{2+}$ Uniporter and other Transporters}

Ionophores are central to the study of highly polarized membranes, such as that of neurons and their mitochondria. Ionophores modify the ion permeability of lipid bilayers, typically lacking selectivity towards the multiple membranes in a cell [54]. Some ionophores form relatively non-selective cationic channels (e.g. gramicidin), whereas others are selective mobile carriers catalyzing the electrogenic uniport of a single ion [e.g. $\mathrm{H}^{+}$(protonophores), $\mathrm{K}^{+}$ (valinomycin), or $\mathrm{Ca}^{2+}$ (ferutinin)], or the electroneutral antiport/exchange of two different ions [e.g. $\mathrm{K}^{+} / \mathrm{H}^{+}$(nigericin), $\mathrm{Ca}^{2+} / 2 \mathrm{H}^{+}$(ionomycin or calcimycin)] [14,55].

Protonophores, most commonly FCCP or CCCP, increase $\mathrm{H}^{+}$permeability of the inner mitochondrial membrane, decreasing $\Delta \mathrm{p}$ and uncoupling respiration from ATP synthesis. Protonophores only partially mimic the endogenous uncoupling protein UCP-1 [56]. Indeed, UCP-1 operates selectively at the inner mitochondrial membrane where it provides a $\Delta \mathrm{p}$ dependent endogenous $\mathrm{H}^{+}$leak, which does not compromise maximal ATP generation capacity since UCP-1 becomes almost inactive during state 3 respiration (see Section 3) [57]. Conversely, protonophores affect $\mathrm{H}^{+}$gradients across non-mitochondrial membranes, e.g. modifying plasmalemmal and synaptic vesicle transmembrane potentials that are particularly relevant for neuronal physiology. Some selectivity can be achieved by protonophore titration. Indeed, $0.25 \mu \mathrm{M}$ FCCP selectively collapsed $\Delta \psi_{\mathrm{m}}$ in cerebellar neurons, whereas $2.5 \mu \mathrm{M}$ FCCP also collapsed plasma membrane potential $\left(\Delta \psi_{\mathrm{p}}\right)$, as evidenced by simultaneous recording of both potentials [54]. Still, $1 \mu \mathrm{M}$ FCCP increases $\Delta \psi_{\mathrm{p}}$, as shown by patch clamp recordings in hippocampal neurons [58]. Thus, $\Delta \psi_{\mathrm{p}}$ collapse with $2.5 \mu \mathrm{M}$ FCCP likely involves ATP depletion and changes in permeability to ions other than $\mathrm{H}^{+}$. In neurons, the prevailing effect of low FCCP concentrations ('mild-uncoupling') is a decrease in maximal ATP generating capacity, whose consequences outweigh marginal reductions in matrix superoxide levels [59]. Moreover, by increasing mitochondrial $\mathrm{H}^{+}$conductance FCCP reverses ATP synthase, which consumes ATP to extrude $\mathrm{H}^{+}$in a futile attempt to recover $\Delta \mathrm{p}$. This $\mathrm{H}^{+}$cycling will lead to cellular ATP depletion, delayed only by glycolytic ATP availability. Thus, in intact neurons, if the goal is to collapse $\Delta \psi_{\mathrm{m}}$ without consuming cellular ATP, FCCP should be combined with oligomycin. Alternatively, the same goal can be achieved with a respiratory chain inhibitor (e.g. myxothiazol) plus oligomycin, with the advantage of avoiding FCCP-induced $\mathrm{H}^{+}$permeability of non-mitochondrial membranes [8].

Potassium ionophores are useful in isolated mitochondria experiments to equilibrate the transmembrane $\mathrm{K}^{+}$gradient with $\Delta \psi_{\mathrm{m}}$ (valinomycin, $\mathrm{K}^{+}$uniport) or with $\Delta \mathrm{pH}$ (nigericin, $\mathrm{K}^{+} / \mathrm{H}^{+}$antiport; allowing $\Delta \mathrm{p}$ to be expressed solely as $\Delta \psi_{\mathrm{m}}$ ) [60-62]. In neurons, valinomycin depolarizes and swells mitochondria, a property applied to study how mitochondria volume affects their trafficking in neurites [42,63]. Valinomycin and nigericin oppositely modulate neuronal $\Delta \psi_{\mathrm{m}}$ and $\Delta \psi_{\mathrm{p}}$. Valinomycin $\mathrm{K}^{+}$uniport decreases $\Delta \psi_{\mathrm{m}}$ via $\mathrm{K}^{+}$influx, and increases $\Delta \psi_{\mathrm{p}}$ via $\mathrm{K}^{+}$efflux. Conversely, nigericin $\mathrm{K}^{+} / \mathrm{H}^{+}$antiport increases $\Delta \psi_{\mathrm{m}}$ via compensatory response to $\Delta \mathrm{pH}$ collapse, and decreases $\Delta \psi_{\mathrm{p}}$ via plasmalemmal $\mathrm{H}^{+}$influx in exchange for $\mathrm{K}^{+}$ efflux [54]. Moreover, $>1 \mu \mathrm{M}$ nigericin allows extracellular $\mathrm{Na}^{+}$influx, further decreasing neuronal $\Delta \psi_{\mathrm{p}}$ and short-circuiting the $\mathrm{Na}^{+}-\mathrm{K}^{+}$ATPase [64].

Calcium ionophores, typically $\mathrm{Ca}^{2+} / 2 \mathrm{H}^{+}$exchangers such as ionomycin and calcimycin (A23187), are frequently used in neurons for calibrating fluorescent $\mathrm{Ca}^{2+}$ probes, including Fura-2 and derivatives (a condition in which the non-fluorescent $4 \mathrm{Br}$-calcimycin is preferred; 
$[55,65])$. In isolated mitochondria, ionophore-induced $\mathrm{Ca}^{2+} / 2 \mathrm{H}^{+}$exchange is partly compensated by $\mathrm{Ca}^{2+}$ reuptake and increased respiration-driven $\mathrm{H}^{+}$extrusion, leading to futile $\mathrm{Ca}^{2+}$ cycling and uncoupling [66]. In situ, effects of $\mathrm{Ca}^{2+}$ ionophores are more complex, influencing both $\Delta \psi_{\mathrm{m}}$ and $\Delta \psi_{\mathrm{p}}$, and also modifying plasmalemmal and ER ion exchange $[54,55]$. While neutral ionophores $\left(\mathrm{Ca}^{2+} / 2 \mathrm{H}^{+}\right.$exchangers) like calcimycin are frequently used to study $\mathrm{Ca}^{2+}$-dependent neuronal cell death [67], electrogenic $\mathrm{Ca}^{2+}$ uniport with ferutinin may promote a more physiological model of mitochondria $\mathrm{Ca}^{2+}$ overload, involving $\mathrm{Ca}^{2+}$ dependent and cyclosporin A sensitive mPT pore opening [55].

$m P T$ inhibitors like cyclosporin A (CsA; [68]) interfere with cyclophilin-D (a mitochondrial matrix peptidyl-prolyl cis-trans isomerase; [69]), preventing its facilitatory effect on $\mathrm{Ca}^{2+}$-triggered mPT. CsA also binds cytosolic cyclophilin-A, forming a complex that inhibits calcineurin and leads to immunosuppression. When studying neuronal mitochondria in situ it is relevant to discriminate CsA's effect on both targets. For this purpose one might compare experiments with CsA with those performed with tacrolimus (a.k.a. FK-506 or fujimycin), which inhibits calcineurin but not mPT [70]. Alternatively, nonimmunosupressive CsA analogs like $\mathrm{N}$-Me-Val-4-CsA, 6-Me-Ala-CsA, $\mathrm{N}$-Me-5-isoleucineCsA (NIM811), and D-3-MeAla-4-EtVal-CsA (Debio-25), retain cyclophilin-D and mPT inhibition but their complexes with cyclophilin-A fail to inhibit calcineurin [28,71]. Similarly, the unrelated $\mathrm{mPT}$ inhibitor sanglifehrin A does not inhibit calcineurin, binding both cyclophilin-D and cyclophilin-A at distinct sites from CsA [72]. The mPT pore is also inhibited by ATP and ADP, but not by their $\mathrm{Mg}^{2+}$ complexes, nor by other nucleotides that are poorly or not transported by the ANT (e.g. AMP, GDP or GTP). Interestingly, ANT inhibitors oppositely modulate $\mathrm{MPT}$ pore opening probability by trapping ANT in opposite conformations (carboxyatractyloside increases and bongkrekic acid decreases $\mathrm{mPT} \mathrm{Ca}^{2+}$ sensitivity). Thus, despite recent knockout studies showing that ANT and VDAC (voltage dependent anion channel, a.k.a. porin) are not essential for mPT to occur, the ANT does exert a regulatory role [28,73-75].

$\mathrm{Ca}^{2+}$ uniporter inhibitors like ruthenium red (RuRed) inhibit $\mathrm{Ca}^{2+}$ uptake into isolated mitochondria. RuRed exhibits poor membrane permeability and selectivity, significantly affecting other $\mathrm{Ca}^{2+}$ channels (e.g. plasmalemmal L-type, and ER ryanodine-sensitive), which limits it usefulness in intact cells. Comparatively, the analog ruthenium 360 (Ru360) displayed increased potency, selectivity, and membrane permeability in isolated cardiac myocytes, suggesting that Ru360 might be used in intact cells [76]. Microinjected Ru360 was effective in neurons from hippocampal slice cultures, and higher concentrations were reported for counterbalancing illumination-dependent decomposition of the ruthenium complex [77]. More recently, in studies with cultured hippocampal neurons, Ru360 did not modify cytosolic $\mathrm{Ca}^{2+}$ responses to glutamate nor associated changes in mitochondria morphology or $\Delta \psi_{\mathrm{m}}$. However, Ru360 was effective following plasmalemma permeabilization with saponin, thus arguing against Ru360 entering intact neurons [78]. Still, because Ru360 is rapidly oxidized by room air, and prolonged incubation periods are required to load intact cells, it is critical to renew Ru360 with freshly prepared solutions in order to ensure compound integrity in longterm experiments [43].

The mitochondrial $\mathrm{Na}^{+} / \mathrm{Ca}^{2+}$ exchanger is inhibited by CGP-37157 (7-chloro-3,5-dihydro5-phenyl-1H-4,1-benzothiazepine-2-one). Caution is advised when using CGP-37157 in intact neurons. At concentrations required for measurable effects on mitochondrial $\mathrm{Ca}^{2+}$ buffering, CGP-37157 directly inhibits voltage-gated $\mathrm{Ca}^{2+}$ channels preventing depolarization-induced $\mathrm{Ca}^{2+}$ influx [79]. CGP-37157 may also inhibit neuronal NMDA receptors [80], and some plasmalemmal $\mathrm{Na}^{+} / \mathrm{Ca}^{2+}$ exchanger isoforms expressed in neurons [81] (Figure 1, right).

\subsubsection{Disrupting mtDNA, Protein Synthesis, and Trafficking Cytoskeleton}

Mitochondrial DNA is selectively disrupted in eukaryotic cells exposed to ethidium bromide 
(EtBr), chronically producing $\rho^{0}$ cells without a functional respiratory chain and auxotrophic for uridine and pyruvate. $\rho^{0}$ cells can be repopulated with mitochondria from other cells originating cytoplasmic hybrids (cybrids) $[82,83]$. Although EtBr preferentially intercalates mitochondrial double-stranded DNA, mutagenic effects on nuclear DNA cannot be excluded thus prompting development of alternative strategies, e.g. targeted restriction endonucleases [84]. In neurons, EtBr mtDNA disruption was used to investigate the mitochondrial role in axonogenesis [85]. Alternatively to $\mathrm{EtBr}$, the toxic mitochondrial dye rhodamine 6-G also prevents mtDNA transmission. Rhodamine 6-G treated embryonic stem cells can be rescued by fusion with cytoplasts, containing wild-type or mutated mtDNA, and differentiated into neurons for functional studies [86,87].

Mitochondrial protein synthesis is selectively inhibited with chloramphenicol, previously used for studying how mitochondrial translation impacts neuronal differentiation [88]. Conversely, cycloheximide reversibly inhibits cytosolic protein synthesis in neurons, whereas puromycin inhibits both cytosolic and mitochondrial protein synthesis $[89,90]$.

Mitochondrial trafficking cytoskeleton may be selectively disrupted to investigate neuronal mitochondrial motility. Neuronal microtubules are depolymerized by nocodazole or vinblastine, whereas actin filaments are depolymerized or disorganized by latrunculin or cytochalasin $[91,92]$. Taxol and nocodozale, respectively, stabilizing and disrupting neuronal microtubules, were shown to depolarize mitochondria and evoke $\mathrm{Ca}^{2+}$ release. CsA blocked these effects on mitochondria, suggesting that taxol and nocodazole induce mPT [93]. Cytochalasin and nocodazole, respectively, disrupting actin filaments and microtubules, differentially affected the stochastic and directed modes of mitochondrial movement in respiratory neurons [94].

\subsubsection{Additional Tools}

$R N A$ interference allows modulation of in situ mitochondrial function, e.g. preventing expression of fusion/fission related proteins $[95,96]$, or interfering with mitochondrial protein import [97,98]. Moreover, multiple drugs affecting neuronal function can be applied to the study of in situ mitochondria, e.g. tetrodotoxin or veratridin to decrease or increase neuronal activity, respectively [99]. In addition to the experimental modulation addressed in this review, mitochondria are primary or secondary targets for several therapeutic molecules $[100,101]$ and gene-therapy [102].

\section{Oxygen consumption and ATP production}

Mitochondrial oxygen consumption ('respiration') is controlled by cellular ATP turnover ('respiratory control'), and directly proportional to $\mathrm{H}^{+}$current across the inner mitochondrial membrane. This $\mathrm{H}^{+}$current comprises $\mathrm{H}^{+}$flow through ATP synthase and $\mathrm{H}^{+}$leaks. Importantly, respiration driving $\mathrm{H}^{+}$leaks changes in a 'non-ohmic' manner, i.e., increases disproportionately to $\Delta \mathrm{p}$ at high membrane potential [14]. In neurons, ATP is primarily produced by mitochondria when compared with glycolysis, and mostly spent in energizing plasmalemmal $\mathrm{Na}^{+} / \mathrm{K}^{+}$- and $\mathrm{Ca}^{2+}$-ATPases in order to maintain ion gradients and thus excitability [1]. Monitoring of mitochondrial respiratory rates with oxygen electrodes provides valuable quantitative information on: (i) mitochondrial ATP synthesis; (ii) magnitude of the $\mathrm{H}^{+}$leak, i.e., uncoupling; and (iii) spare respiratory capacity, i.e., the mitochondrial ability to fulfil increased ATP demand.

The respiratory control ratio ( $\mathrm{RCR})$ is a classical parameter indicating the coupling efficiency of oxidative phosphorylation. RCR is calculated by dividing the respiration rate when ATP synthesis is maximal (state 3) by the respiration rate without ATP synthesis, driven solely by $\mathrm{H}^{+}$leaks (state 4). For isolated mitochondria suspended in cytosolic-like 
buffer (high $\mathrm{K}^{+}$), containing phosphate and substrate, the maximal ADP-evoked respiration provides the state 3 rate. Subsequent ATP synthase inhibition with oligomycin provides the state 4 rate. In intact neurons, respiration can be assessed by monitoring downstream oxygen levels in the buffer perfusing coverslip-attached cells $[103,104]$, or by using microplate-based respirometry $[105,106]$.

In situ neuronal mitochondria typically respire in 'state 31/2' [107], between state 3 and 4, with submaximal ATP synthesis. Oligomycin places mitochondria in state 4, whereas FCCP induces maximal uncoupled respiration. Full mitochondrial complex I and III inhibition with rotenone and myxothiazol, respectively, provides non-mitochondrial respiration that should be subtracted from all measurements. The difference between basal (state $\left.3 \frac{1 / 2}{2}\right)$ and oligomycin respiration (state 4) is an approximate measure of basal ATP turnover. The difference from FCCP respiration indicates spare respiratory capacity. With the proviso that FCCP respiration is not limited by ATP synthase activity, but represents maximal substrate oxidation capacity, comparing FCCP respiration with that reached during neuronal challenges, such as NMDA receptor activation, allows estimates of whether a lack of spare ATP generating capacity limits neuronal survival $[108,109]$. In practice, oligomycin respiration underestimates basal ATP turnover because ATP synthase inhibition increases $\Delta p$ and, consequently, the nonohmic conductance, thus overestimating $\mathrm{H}^{+}$leaks in state $3 \frac{1}{2}$ [110]. Assessing the variable impact of non-ohmic $\mathrm{H}^{+}$conductance on coupling efficiency is feasible in isolated mitochondria, namely with the systems approach 'modular kinetic analysis' [111]. Simultaneous oxygen consumption and $\Delta \psi_{\mathrm{m}}$ measurements while substrate oxidation is titrated with FCCP, and state 4 respiration titrated with complex inhibitor (rotenone or malonate for complex I or II substrates, respectively), allows coupling efficiency calculations at any chosen $\Delta \psi_{\mathrm{m}}$ value [62], thus accounting for the non-ohmic conductance and possibly identifying functional differences between control and test mitochondria.

Measuring neuronal ATP levels may provide information on mitochondrial ATP synthesis. In such measurements one should consider that: $(i)$ glycolysis also contributes for cellular ATP and may be increased by Pasteur effect masking mitochondrial dysfunction [112]; (ii) presence of non-neuronal cells, e.g. astrocytes, influences global ATP measurements [113]; and (iii) ATP synthase reversal causes mitochondria to consume rather than generate ATP. The ATP content of neuronal populations can be quantified at specific time-points using luciferin-luciferase luminescence or HPLC techniques, which allow additional measurements [114-116]. Single-neuron dynamic changes in $[A T P]_{i}$ can be monitored indirectly via changes in $\left[\mathrm{Mg}^{2+}\right]_{\mathrm{i}}$. Cytosolic $\mathrm{Mg}^{2+}$ normally binds ATP and is released upon ATP hydrolysis, causing free $\left[\mathrm{Mg}^{2+}\right]_{\mathrm{i}}$ to inversely correlate with $[\mathrm{ATP}]_{\mathrm{i}}$. This can be assessed by real-time fluorescence microscopy using $\mathrm{Mg}^{2+}$-sensitive indicators like Magnesium Green $\left(K_{d} \mathrm{Mg}^{2+} \sim 1 \mathrm{mM} ; K_{d} \mathrm{Ca}^{2+}\right.$ $\sim 6 \mu \mathrm{M})$ or Mag-Fura-2 $\left(K_{d} \mathrm{Mg}^{2+} \sim 2 \mathrm{mM} ; K_{d} \mathrm{Ca}^{2+} \sim 25 \mu \mathrm{M}\right)$. Simultaneous recordings with a spectrally distinct and selective $\mathrm{Ca}^{2+}$ indicator, e.g. Magnesium Green + Fura-2, allow correction for $\left[\mathrm{Ca}^{2+}\right]_{i}$ changes $[117,118]$. Also, real-time monitoring of intracellular ATP or ATP:ADP ratio may be performed with genetically encoded reporters [119-121]. Furthermore, qualitative information on whether neuronal mitochondria are generating or consuming ATP can be inferred from the 'oligomycin null-point test' [122] using $\Delta \psi_{\mathrm{m}^{-}}$ sensitive probes, as addressed below.

\section{Mitochondrial and plasma membrane potentials}

Mitochondrial membrane potential $\left(\Delta \psi_{\mathrm{m}}\right)$ measurements follow the Nernstian distribution of lipophilic cations, which cross membranes and re-equilibrate in response to changes in electrochemical potential gradients. Isolated mitochondria $\Delta \psi_{\mathrm{m}}$ is traditionally assessed with 
tetraphenylphosphonium $\left(\mathrm{TPP}^{+}\right)$and electrode-based detection, whereas in situ $\Delta \psi_{\mathrm{m}}$ measurements frequently use fluorescent detection of rhodamine derived probes, most notably, tetramethylrhodamine methyl or ethyl ester $\left(\mathrm{TMRM}^{+}\right.$or $\mathrm{TMRE}^{+}$, respectively) and rhodamine-123 (Rh123) [123]. Interpreting fluorescence changes in neurons loaded with these probes is far from trivial, but observing three important principles minimises misinterpretations. First, lipophilic cations are $\Delta \psi_{\mathrm{m}}$-'sensitive', not $\Delta \psi_{\mathrm{m}}$-'specific'. They partition across plasma and mitochondrial membranes and respond to $\Delta \psi_{\mathrm{p}}$ and $\Delta \psi_{\mathrm{m}}$ changes (Figure 1, bottom right: $\mathrm{TMRM}^{+}$). Second, redistribution is much faster across the mitochondrial vs. plasma membrane due to surface/volume differences. Third, when matrix probe reaches an aggregation threshold, fluorescence is quenched becoming nonlinear with concentration $[15,54]$.

Quench vs. non-quench (or equilibrium) are two different experimental approaches with $\Delta \psi_{\mathrm{m}}$-sensitive probes. Their interpretation varies significantly, and probe titration is essential to ensure the desired approach. In equilibrium conditions, using low probe concentrations to avoid matrix quenching, whole-cell fluorescence originates mostly $(\sim 75 \%)$ from polarized mitochondria (for $\Delta \psi_{\mathrm{m}} \sim 150 \mathrm{mV}$ and $1 \%$ matrix/cytoplasm volume; [15]). Under these conditions, whole-cell fluorescence is theoretically related to $\Delta \psi_{\mathrm{m}}$. Still, variation in matrix/cytoplasm volume or in $\Delta \psi_{\mathrm{p}}$ may influence differences among cells. In quench mode, resting whole-cell fluorescence does not reflect $\Delta \psi_{\mathrm{m}}$ because matrix probe aggregation blunts concentration differences. Nevertheless, because mitochondrial hyperpolarization or depolarization drives matrix probe influx or efflux, respectively, these changes in $\Delta \psi_{\mathrm{m}}$ can be transiently detected in cytosolic or whole-cell fluorescence $[8,15]$.

Rh123 is less permeable than $T M R M^{+}$, thus equilibrating slowly across the plasma membrane. Hence, short-term experiments using Rh123 in quench mode allow dynamic $\Delta \psi_{\mathrm{m}}$ recording with less interference from $\Delta \psi_{\mathrm{p}}[122,124,125]$. For $\mathrm{TMRM}^{+}$, the ambiguity in relating changes in fluorescence to $\Delta \psi_{\mathrm{m}}$ or $\Delta \psi_{\mathrm{p}}$ can be circumvented via simultaneous recordings with an anionic $\Delta \psi_{\mathrm{p}}$ probe, and with the assistance of computer algorithms [54]. Simultaneous $\Delta \psi_{\mathrm{m}} / \Delta \psi_{\mathrm{p}}$ and $\left[\mathrm{Ca}^{2+}\right]_{\mathrm{i}}$ measurements are feasible in intact neurons. Stepwise extracellular $\mathrm{K}^{+}: \mathrm{Na}^{+}$replacement and the Goldman equation allow $\Delta \psi_{\mathrm{p}}$ probe calibration, whereas maximal and minimal $\left(0 \mathrm{Ca}^{2+}\right.$ :EGTA) ratiometric signals with ionophore allow $\left[\mathrm{Ca}^{2+}\right]_{\text {i }}$ probe calibration $[54,126]$.

The oligomycin null-point test distinguishes neurons with competent (ATP-producing) mitochondria from those with damaged (ATP-consuming) mitochondria. With sufficient glycolytic ATP, damaged mitochondria can hold $\Delta \psi_{\mathrm{m}}$ by ATP synthase reversal and load efficiently with $\Delta \psi_{\mathrm{m}}$-sensitive probes. Oligomycin hyperpolarizes ATP-producing mitochondria by preventing $\mathrm{F}_{0} \mathrm{H}^{+}$re-entry. Conversely, oligomycin depolarizes ATPconsuming mitochondria by preventing $\mathrm{F}_{0} \mathrm{H}^{+}$extrusion. Under quench conditions, hyperpolarization decreases whole-cell fluorescence by driving cytoplasmic probe to the matrix quenching environment. Depolarization increases whole-cell fuorescence as the probe exits the matrix towards the cytosol. Terminating experiments with full $\Delta \psi_{\mathrm{m}}$ collapse by FCCP provides positive control for quenching conditions [122,127,128].

A major source of artefacts with $\Delta \psi_{m}$-sensitive probes is their efficient extrusion by the multi-drug resistance (MDR) pump, P-glycoprotein, expressed by some cells-lines used as "neuronal models". To avoid erroneous interpretations of decreased $\Delta \psi_{\mathrm{m}}$ in such cells, one should test whether MDR inhibitors like verapamil or CsA significantly increase probeloading efficiency. Conversely, to avoid erroneous interpretations of mPT inhibition when CsA increases probe fluorescence, one should test whether verapamil is devoid of the same effect [129], and/or use other mPT inhibitors (see Section 2.4.2). Note that, in neurons, $\mathrm{Ca}^{2+}$ channel blockade by verapamil may confound data interpretation. 


\section{Mitochondrial-dependent calcium handling}

$\mathrm{Ca}^{2+}$-buffering capacity is a frequently assessed mitochondrial function. A high capacity affords protection from $\mathrm{Ca}^{2+}$-induced damage, e.g. following excitotoxic $\mathrm{Ca}^{2+}$ elevation. Conversely, a decreased capacity suggests mitochondrial dysfunction. Measurements in isolated mitochondria typically monitor how much $\mathrm{Ca}^{2+}$ (nmol/mg protein) the population can buffer before generalized mPT. $\mathrm{Ca}^{2+}$-sensitive electrodes or fluorescent probes, e.g. CalciumGreen, allow continuous extra-mitochondrial $\left[\mathrm{Ca}^{2+}\right]$ monitoring. Mitochondria concentration, buffer composition, notably in phosphate and adenine nucleotides, and the mode of $\mathrm{Ca}^{2+}$ addition, repetitive bolus vs. continuous infusion, significantly impact maximal $\mathrm{Ca}^{2+}$ buffering capacity $[104,130]$. Non-mitochondrial $\mathrm{Ca}^{2+}$-handling mechanisms and glycolytic ATP in intact neurons complicate assessment of in situ mitochondrial $\mathrm{Ca}^{2+}$-buffering [127].

Mitochondrial-dependent $\mathrm{Ca}^{2+}$-handling, i.e., without glycolytic ATP interference, can be assessed by replacing glucose with 2-deoxy-D-glucose plus pyruvate as mitochondria substrate. This is particularly relevant in cell-lines where abundant glycolysis obscures mitochondrial $\mathrm{Ca}^{2+}$-handling [65]. Fluorescent $\mathrm{Ca}^{2+}$-probes carrying a delocalized positive charge, e.g. rhod-2 and analogues, accumulate preferentially in mitochondria but require appropriate measures to minimize extra-mitochondrial signal [8]. In addition, genetically encoded mitochondria-targeted $\mathrm{Ca}^{2+}$-sensors provide elegant ways to monitor mitochondrial $\mathrm{Ca}^{2+}$-handling in intact cells, including in vivo. Novel aequorin and GFP-based $\mathrm{Ca}^{2+}$ sensors are not without limitations, but there have been improvements in selective organelle targeting, $\left[\mathrm{Ca}^{2+}\right]_{\mathrm{i}}$ detection range, and imaging technology to deal with low photon yield and fluorescent signal/noise ratios $[131,132]$. Importantly, dynamic measurements with mitochondrial matrix $\mathrm{Ca}^{2+}$ probes report changes in free (not total) $\mathrm{Ca}^{2+}$ levels. Due to formation of $\mathrm{Ca}^{2+}$-phosphate complexes, free $\mathrm{Ca}^{2+}$ is buffered at $\sim 0.2-5 \mu \mathrm{M}$ in spite of continuous increase in total matrix $\mathrm{Ca}^{2+}[24,27]$. Inducing $\mathrm{Ca}^{2+}$ release with FCCP, and monitoring the area under the curve with a low affinity ratiometric $\mathrm{Ca}^{2+}$-probe, estimates total $\mathrm{Ca}^{2+}$ buffered by neuronal mitochondria during glutamate receptor activation [133]. Recently, we proposed a strategy for comparisons of in situ mitochondrial $\mathrm{Ca}^{2+}$-buffering capacity, using neurons and astrocytes from different brain regions, with calibration for different rates of $\left[\mathrm{Ca}^{2+}\right]_{i}$ elevation and mitochondrial content [126].

In situ evaluation of $m P T$ in neurons has been performed by the calcein/cobalt-quenching technique $[93,134]$. Cells loaded with sufficient calcein-AM display both mitochondrial and cytosolic fluorescence. However, the latter is selectively quenched with cobalt $\left(\mathrm{Co}^{2+}\right)$, which does not permeate an intact inner mitochondrial membrane. Induction of $\mathrm{mPT}$ releases mitochondrial entrapped calcein, detected by mitochondrial fluorescence decay [135]. With $\mathrm{Co}^{2+}$ in the cytosol, mitochondria fluorescence decay may also be due to $\mathrm{Co}^{2+}$ influx and calcein quenching [136]. Different cell-types exhibit different $\mathrm{Co}^{2+}$ permeability. In neurons, $\mathrm{Co}^{2+}$ uptake occurs via active AMPA/kainate receptors, thus varying with receptor density and neuronal activity. Also, single neurons display incomplete co-localization of calcein and $\Delta \psi_{\mathrm{m}}$-sensitive probes, so their combination is recommended to identify calcein-loaded mitochondria [134]. $\mathrm{Co}^{2+}$ microinjection may overcome permeability issues, but high cytosolic $\mathrm{Co}^{2+}$ may be problematic. Although $\mathrm{Co}^{2+}$ is not transported by the $\mathrm{Ca}^{2+}$ uniporter, it inhibits $\mathrm{Ca}^{2+}$ uptake and decreases mitochondria respiration [135]. An alternative technique, described in non-neuronal cells, combines two fluorescent probes to discriminate polarized from depolarized (possibly via mPT) mitochondria within the same cell. The two probes, Mitotracker Green (MTG) and $\mathrm{TMRM}^{+}$, accumulate electrophoretically into mitochondria, but MTG establishes covalent bonds becoming retained after depolarization. By imaging fluorescence resonance energy transfer (FRET) between MTG and $\mathrm{TMRM}^{+}$, depolarized 
mitochondria (MTG only) were identified against a background of hundreds of polarized $\left(\mathrm{MTG}+\mathrm{TMRM}^{+}\right)$mitochondria [137].

\section{Biogenesis, trafficking, fusion and fission}

Mitochondrial biogenesis indicators include mtDNA copy number, mitochondria mass/volume, transcription factors (e.g. PGC-1 $\alpha$, mtTFA, NRF-1 and NRF-2), and mitochondrial proteins (e.g. cytochrome oxidase and ATP synthase subunits) [35]. Biogenesis has been assessed in populations of cultured neurons and brain tissue, namely in the context of diabetic neuropathy or stroke, using hyperglycaemic or hypoxic-ischemic injury, respectively [31,138]. Moreover, differential biogenesis between single neurons and within subneuronal compartments can be investigated by incorporating deoxyuridine derivatives into newly synthesized mtDNA [139].

Labelling mitochondria with fluorescent probes, e.g. lipophilic cations or genetically encoded mitochondrially-targeted proteins [140-142], allows monitoring and quantification of mitochondria dynamics using video-microscopy and digital image processing techniques, respectively. In any case, care should be taken to minimize mitochondrial toxicity [143]. Mitochondrial fractional occupancy measurements $\left(\Sigma_{\text {mitochondria length }} / \Sigma_{\text {neurites }}\right.$ length, using skeletonized images; [99]) provide information on mitochondrial biogenesis. Trafficking information can be derived from time-lapse image acquisition and processing, most often requiring manual mitochondria tracking [3], although some measurements can be automated, e.g. using an 'optical flow' method [144]. Several analysis strategies have been described, notably, 'single particle analysis', 'dwell areas' visited by mitochondria in a given time interval, and 'kymographs', i.e., time-projections of fluorescence intensities across neuritic lines, where slopes are proportional to speed, and direction can be inferred (see [38]). Levels of motor or adaptor proteins and their association with mitochondria provide additional trafficking-related information [145,146]. Fusion and fission can be estimated from the number and size of mitochondrial particles [95], as well as by quantifying levels of fusion and fission related GTPases [96,138,147].

\section{Other techniques and concluding remarks}

In addition to the parameters and techniques addressed in this review, multiple others assist the study of neuronal mitochondrial function. E.g. Changes in $\mathrm{NAD}(\mathrm{P}) \mathrm{H}$ and $\mathrm{FADH}_{2}$ autofluorescence monitor mitochondria redox state in isolated suspensions, neurons or brain slices [124,148,149]; Oxidation of dichlorofluorescein, dihydroethidine or its mitochondrially-targeted derivative MitoSox estimate neuronal ROS formation, with some limitations related to $\mathrm{pH}$ sensitivity and $\Delta \psi_{\mathrm{m}}$-dependent probe localization $[59,107,118]$; Apoptotic protein release, e.g. cytochrome $c$, signals mitochondria-dependent apoptosis [150]; Sequential histochemical staining for cytochrome c oxidase and succinate dehydrogenase activities identifies neurons with dysfunctional mitochondria, where mtDNA mutations can be probed via laser microdissection and polymerase chain reaction [151,152].

The study of neuronal mitochondria is clearly enriched with many complementary experimental approaches, allowing researchers to test disease-induced mitochondrial dysfunction and protective pharmacological strategies. Given the wide variety of possible research subjects and experimental models, choosing a single 'best' technique is a utopian endeavour. Nevertheless, given their central roles in mitochondrial activity, $\Delta \psi_{\mathrm{m}}, \mathrm{Ca}^{2+}$ buffering and the highly informative respiration measurements are good choices both for isolated and in situ mitochondria. The researcher interested in additional events will certainly 
appreciate the alluring mitochondrial dynamics.

\section{Acknowledgments}

The author is grateful to Michael Duchen (University College London, UK), David Nicholls (Buck Institute for Age Research, USA), and Robert Lightowlers (Newcastle University, UK) for thoughtful comments and helpful suggestions.

\section{References}

[1]Kann O, Kovacs R. Mitochondria and neuronal activity. Am J Physiol Cell Physiol 2007; 292: C641-57.

[2]Szabadkai G, Duchen MR. Mitochondria: the hub of cellular $\mathrm{Ca}^{2+}$ signaling. Physiology (Bethesda) 2008; 23: 84-94.

[3]Chang DT, Reynolds IJ. Mitochondrial trafficking and morphology in healthy and injured neurons. Prog Neurobiol 2006; 80: 241-68.

[4] Onyango IG, Lu J, Rodova M, Lezi E, Crafter AB, Swerdlow RH. Regulation of neuron mitochondrial biogenesis and relevance to brain health. Biochim Biophys Acta 2010; 1802: 228-34.

[5]Jahani-Asl A, Germain M, Slack RS. Mitochondria: Joining forces to thwart cell death. Biochim Biophys Acta 2010; 1802: 162-6.

[6]Chen H, Chan DC. Mitochondrial dynamics--fusion, fission, movement, and mitophagy-in neurodegenerative diseases. Hum Mol Genet 2009; 18: R169-76.

[7]Twig G, Hyde B, Shirihai OS. Mitochondrial fusion, fission and autophagy as a quality control axis: the bioenergetic view. Biochim Biophys Acta 2008; 1777: 1092-7.

[8]Duchen MR, Surin A, Jacobson J. Imaging mitochondrial function in intact cells. Methods Enzymol 2003; 361: 353-89.

[9]Embley TM, Martin W. Eukaryotic evolution, changes and challenges. Nature 2006; 440: 623-30.

[10] Hjort K, Goldberg AV, Tsaousis AD, Hirt RP, Embley TM. Diversity and reductive evolution of mitochondria among microbial eukaryotes. Philos Trans R Soc Lond B Biol Sci 2010; 365: 713-27.

[11] Zeviani M, Di Donato S. Mitochondrial disorders. Brain 2004; 127: 2153-72.

[12] Sims NR, Muyderman H. Mitochondria, oxidative metabolism and cell death in stroke. Biochim Biophys Acta 2010; 1802: 80-91.

[13] Mattson MP, Gleichmann M, Cheng A. Mitochondria in neuroplasticity and neurological disorders. Neuron 2008; 60: 748-66.

[14] Nicholls DG, Budd SL. Mitochondria and neuronal survival. Physiol Rev 2000; 80: 315-60.

[15] Nicholls DG, Ward MW. Mitochondrial membrane potential and neuronal glutamate excitotoxicity: mortality and millivolts. Trends Neurosci 2000; 23: 166-74.

[16] Campanella M, Parker N, Tan CH, Hall AM, Duchen MR. IF(1): setting the pace of the F(1)F(o)-ATP synthase. Trends Biochem Sci 2009; 34: 343-50.

[17] Brand MD, Affourtit C, Esteves TC, Green K, Lambert AJ, Miwa S, et al. Mitochondrial superoxide: production, biological effects, and activation of uncoupling proteins. Free Radic Biol Med 2004; 37: 755-67.

[18] Brand MD, Brindle KM, Buckingham JA, Harper JA, Rolfe DF, Stuart JA. The significance and mechanism of mitochondrial proton conductance. Int J Obes Relat Metab Disord 1999; 23: S4-11. 
[19] Nicholls DG. A history of UCP1. Biochem Soc Trans 2001; 29: 751-5.

[20] Brand MD, Pakay JL, Ocloo A, Kokoszka J, Wallace DC, Brookes PS, et al. The basal proton conductance of mitochondria depends on adenine nucleotide translocase content. Biochem J 2005; 392: 353-62.

[21] Nicholls DG. Mitochondria and calcium signaling. Cell Calcium 2005; 38: 311-7.

[22] Duchen MR, Verkhratsky A, Muallem S. Mitochondria and calcium in health and disease. Cell Calcium 2008; 44:1-5.

[23] Graier WF, Frieden M, Malli R. Mitochondria and $\mathrm{Ca}(2+)$ signaling: old guests, new functions. Pflugers Arch 2007; 455: 375-96.

[24] Nicholls DG. Mitochondrial calcium function and dysfunction in the central nervous system. Biochim Biophys Acta 2009; 1787: 1416-24.

[25] O'Rourke B. Mitochondrial ion channels. Annu Rev Physiol 2007; 69: 19-49.

[26] Castaldo P, Cataldi M, Magi S, Lariccia V, Arcangeli S, Amoroso S. Role of the mitochondrial sodium/calcium exchanger in neuronal physiology and in the pathogenesis of neurological diseases. Prog Neurobiol 2009; 87: 58-79.

[27] Nicholls DG, Chalmers S. The integration of mitochondrial calcium transport and storage. J Bioenerg Biomembr 2004; 36: 277-81.

[28] Halestrap AP. What is the mitochondrial permeability transition pore? J Mol Cell Cardiol 2009; 46: 821-31.

[29] Sullivan PG, Rabchevsky AG, Waldmeier PC, Springer JE. Mitochondrial permeability transition in CNS trauma: cause or effect of neuronal cell death? J Neurosci Res 2005; 79: 231-9.

[30] Kristal BS, Stavrovskaya IG, Narayanan MV, Krasnikov BF, Brown AM, Beal MF, et al. The mitochondrial permeability transition as a target for neuroprotection. J Bioenerg Biomembr 2004; 36: 309-12.

[31] Yin W, Signore AP, Iwai M, Cao G, Gao Y, Chen J. Rapidly increased neuronal mitochondrial biogenesis after hypoxic-ischemic brain injury. Stroke. 2008; 39: 3057-63.

[32] Lane N. Power, Sex, Suicide: Mitochondria and the Meaning of Life: Oxford University Press 2005.

[33] Dyall SD, Brown MT, Johnson PJ. Ancient invasions: from endosymbionts to organelles. Science 2004; 304: 253-7.

[34] Pfanner N, Geissler A. Versatility of the mitochondrial protein import machinery. Nat Rev Mol Cell Biol 2001; 2: 339-49.

[35] Medeiros DM. Assessing mitochondria biogenesis. Methods 2008; 46: 288-94.

[36] Knott AB, Perkins G, Schwarzenbacher R, Bossy-Wetzel E. Mitochondrial fragmentation in neurodegeneration. Nat Rev Neurosci 2008; 9: 505-18.

[37] Liesa M, Palacin M, Zorzano A. Mitochondrial dynamics in mammalian health and disease. Physiol Rev 2009; 89: 799-845.

[38] Mironov SL. Complexity of mitochondrial dynamics in neurons and its control by ADP produced during synaptic activity. Int J Biochem Cell Biol 2009; 41: 2005-14.

[39] Macaskill AF, Rinholm JE, Twelvetrees AE, Arancibia-Carcamo IL, Muir J, Fransson A, et al. Miro1 is a calcium sensor for glutamate receptor-dependent localization of mitochondria at synapses. Neuron 2009; 61: 541-55.

[40] Saotome M, Safiulina D, Szabadkai G, Das S, Fransson A, Aspenstrom P, et al. Bidirectional $\mathrm{Ca}^{2+}$-dependent control of mitochondrial dynamics by the Miro GTPase. Proc Natl Acad Sci USA 2008; 105: 20728-33.

[41] Rintoul GL, Filiano AJ, Brocard JB, Kress GJ, Reynolds IJ. Glutamate decreases mitochondrial size and movement in primary forebrain neurons. J Neurosci 2003; 23: 7881-8. 
[42] Kaasik A, Safiulina D, Choubey V, Kuum M, Zharkovsky A, Veksler V. Mitochondrial swelling impairs the transport of organelles in cerebellar granule neurons. J Biol Chem 2007; 282: 32821-6.

[43] Abramov AY, Duchen MR. Mechanisms underlying the loss of mitochondrial membrane potential in glutamate excitotoxicity. Biochim Biophys Acta 2008; 1777: 95364.

[44] Degli Esposti M. Inhibitors of NADH-ubiquinone reductase: an overview. Biochim Biophys Acta 1998; 1364: 222-35.

[45] Kotake Y, Ohta S. MPP+ analogs acting on mitochondria and inducing neurodegeneration. Curr Med Chem 2003; 10: 2507-16.

[46] Brouillet E, Jacquard C, Bizat N, Blum D. 3-Nitropropionic acid: a mitochondrial toxin to uncover physiopathological mechanisms underlying striatal degeneration in Huntington's disease. J Neurochem 2005; 95: 1521-40.

[47] Turrens JF, Alexandre A, Lehninger AL. Ubisemiquinone is the electron donor for superoxide formation by complex III of heart mitochondria. Arch Biochem Biophys 1985; 237: 408-14.

[48] Vesce S, Kirk L, Nicholls DG. Relationships between superoxide levels and delayed calcium deregulation in cultured cerebellar granule cells exposed continuously to glutamate. J Neurochem 2004; 90: 683-93.

[49] Dubinsky JM, Rothman SM. Intracellular calcium concentrations during "chemical hypoxia" and excitotoxic neuronal injury. J Neurosci 1991; 11:2545-51.

[50] Hong S, Pedersen PL. ATP synthase and the actions of inhibitors utilized to study its roles in human health, disease, and other scientific areas. Microbiol Mol Biol Rev 2008; 72: 590-641.

[51] Arato-Oshima T, Matsui H, Wakizaka A, Homareda H. Mechanism responsible for oligomycin-induced occlusion of $\mathrm{Na}+$ within $\mathrm{Na} / \mathrm{K}-\mathrm{ATPase}$. J Biol Chem 1996; 271: 25604-10.

[52] Gledhill JR, Walker JE. Inhibitors of the catalytic domain of mitochondrial ATP synthase. Biochem Soc Trans 2006; 34: 989-92.

[53] Gledhill JR, Walker JE. Inhibition sites in F1-ATPase from bovine heart mitochondria. Biochem J 2005; 386: 591-8.

[54] Nicholls DG. Simultaneous monitoring of ionophore- and inhibitor-mediated plasma and mitochondrial membrane potential changes in cultured neurons. J Biol Chem 2006; 281: 14864-74.

[55] Abramov AY, Duchen MR. Actions of ionomycin, 4-BrA23187 and a novel electrogenic $\mathrm{Ca}^{2+}$ ionophore on mitochondria in intact cells. Cell Calcium 2003; 33: 10112.

[56] Heaton GM, Wagenvoord RJ, Kemp A, Jr., Nicholls DG. Brown-adipose-tissue mitochondria: photoaffinity labelling of the regulatory site of energy dissipation. Eur $\mathbf{J}$ Biochem 1978; 82: 515-21.

[57] Nicholls DG. The physiological regulation of uncoupling proteins. Biochim Biophys Acta 2006; 1757: 459-66.

[58] Nowicky AV, Duchen MR. Changes in $\left[\mathrm{Ca}^{2+}\right]_{\mathrm{i}}$ and membrane currents during impaired mitochondrial metabolism in dissociated rat hippocampal neurons. J Physiol 1998; 507: $131-45$.

[59] Johnson-Cadwell LI, Jekabsons MB, Wang A, Polster BM, Nicholls DG. 'Mild Uncoupling' does not decrease mitochondrial superoxide levels in cultured cerebellar granule neurons but decreases spare respiratory capacity and increases toxicity to glutamate and oxidative stress. J Neurochem 2007; 101: 1619-31. 
[60] Nicholls DG. The influence of respiration and ATP hydrolysis on the protonelectrochemical gradient across the inner membrane of rat-liver mitochondria as determined by ion distribution. Eur J Biochem 1974; 50: 305-15.

[61] Lambert AJ, Brand MD. Superoxide production by NADH:ubiquinone oxidoreductase (complex I) depends on the $\mathrm{pH}$ gradient across the mitochondrial inner membrane. Biochem J 2004; 382: 511-7.

[62] Amo T, Yadava N, Oh R, Nicholls DG, Brand MD. Experimental assessment of bioenergetic differences caused by the common European mitochondrial DNA haplogroups H and T. Gene 2008; 411: 69-76.

[63] Safiulina D, Veksler V, Zharkovsky A, Kaasik A. Loss of mitochondrial membrane potential is associated with increase in mitochondrial volume: physiological role in neurones. J Cell Physiol 2006; 206: 347-53.

[64] Erecinska M, Nelson D, Dagani F, Deas J, Silver IA. Relations between intracellular ions and energy metabolism under acidotic conditions: a study with nigericin in synaptosomes, neurons, and C6 glioma cells. J Neurochem 1993; 61: 1356-68.

[65] Oliveira JM, Chen S, Almeida S, Riley R, Goncalves J, Oliveira CR, et al. Mitochondrial-dependent $\mathrm{Ca} 2+$ handling in Huntington's disease striatal cells: effect of histone deacetylase inhibitors. J Neurosci 2006; 26: 11174-86.

[66] Reed PW, Lardy HA. A23187: a divalent cation ionophore. J Biol Chem 1972; 247: 6970-7.

[67] Petersen A, Castilho RF, Hansson O, Wieloch T, Brundin P. Oxidative stress, mitochondrial permeability transition and activation of caspases in calcium ionophore A23187-induced death of cultured striatal neurons. Brain Res 2000; 857: 20-9.

[68] Crompton M, Ellinger H, Costi A. Inhibition by cyclosporin A of a $\mathrm{Ca}^{2+}$-dependent pore in heart mitochondria activated by inorganic phosphate and oxidative stress. Biochem $\mathrm{J}$ 1988; 255: 357-60.

[69] Halestrap AP, Davidson AM. Inhibition of Ca2(+)-induced large-amplitude swelling of liver and heart mitochondria by cyclosporin is probably caused by the inhibitor binding to mitochondrial-matrix peptidyl-prolyl cis-trans isomerase and preventing it interacting with the adenine nucleotide translocase. Biochem J 1990; 268: 153-60.

[70] Friberg H, Ferrand-Drake M, Bengtsson F, Halestrap AP, Wieloch T. Cyclosporin A, but not FK 506, protects mitochondria and neurons against hypoglycemic damage and implicates the mitochondrial permeability transition in cell death. J Neurosci 1998; 18 : 5151-9.

[71] Khaspekov L, Friberg H, Halestrap A, Viktorov I, Wieloch T. Cyclosporin A and its nonimmunosuppressive analogue $\mathrm{N}-\mathrm{Me}-\mathrm{Val}-4$-cyclosporin A mitigate glucose/oxygen deprivation-induced damage to rat cultured hippocampal neurons. Eur J Neurosci 1999; 11: 3194-8.

[72] Clarke SJ, McStay GP, Halestrap AP. Sanglifehrin A acts as a potent inhibitor of the mitochondrial permeability transition and reperfusion injury of the heart by binding to cyclophilin-D at a different site from cyclosporin A. J Biol Chem 2002; 277: 34793-9.

[73] Halestrap AP. Mitochondrial permeability: dual role for the ADP/ATP translocator? Nature 2004; 430: $1 \mathrm{p}$ following 983.

[74] Klingenberg M. The ADP and ATP transport in mitochondria and its carrier. Biochim Biophys Acta 2008; 1778: 1978-2021.

[75] Kokoszka JE, Waymire KG, Levy SE, Sligh JE, Cai J, Jones DP, et al. The ADP/ATP translocator is not essential for the mitochondrial permeability transition pore. Nature 2004; 427: 461-5.

[76] Matlib MA, Zhou Z, Knight S, Ahmed S, Choi KM, Krause-Bauer J, et al. Oxygenbridged dinuclear ruthenium amine complex specifically inhibits $\mathrm{Ca}^{2+}$ uptake into 
mitochondria in vitro and in situ in single cardiac myocytes. J Biol Chem 1998; 273: 10223-31.

[77] Kovacs R, Kardos J, Heinemann U, Kann O. Mitochondrial calcium ion and membrane potential transients follow the pattern of epileptiform discharges in hippocampal slice cultures. J Neurosci 2005; 25: 4260-9.

[78] Brustovetsky T, Li V, Brustovetsky N. Stimulation of glutamate receptors in cultured hippocampal neurons causes $\mathrm{Ca}^{2+}$-dependent mitochondrial contraction. Cell Calcium 2009; 46: 18-29.

[79] Baron KT, Thayer SA. CGP37157 modulates mitochondrial $\mathrm{Ca}^{2+}$ homeostasis in cultured rat dorsal root ganglion neurons. Eur J Pharmacol 1997; 340: 295-300.

[80] Scanlon JM, Brocard JB, Stout AK, Reynolds IJ. Pharmacological investigation of mitochondrial $\mathrm{ca}(2+)$ transport in central neurons: studies with CGP-37157, an inhibitor of the mitochondrial $\mathrm{Na}(+)-\mathrm{Ca}(2+)$ exchanger. Cell Calcium 2000; 28: 317-27.

[81] Czyz A, Kiedrowski L. Inhibition of plasmalemmal $\mathrm{Na}(+) / \mathrm{Ca}(2+)$ exchange by mitochondrial $\mathrm{Na}(+) / \mathrm{Ca}(2+)$ exchange inhibitor 7-chloro-5-(2-chlorophenyl)-1,5-dihydro4,1-benzothiazepin-2(3H)-one (CGP-37157) in cerebellar granule cells. Biochem Pharmacol 2003; 66: 2409-11.

[82] King MP, Attardi G. Human cells lacking mtDNA: repopulation with exogenous mitochondria by complementation. Science 1989; 246: 500-3.

[83] Ghosh SS, Swerdlow RH, Miller SW, Sheeman B, Parker WD, Jr., Davis RE. Use of cytoplasmic hybrid cell lines for elucidating the role of mitochondrial dysfunction in Alzheimer's disease and Parkinson's disease. Ann N Y Acad Sci 1999; 893: 176-91.

[84] Kukat A, Kukat C, Brocher J, Schafer I, Krohne G, Trounce IA, et al. Generation of rho0 cells utilizing a mitochondrially targeted restriction endonuclease and comparative analyses. Nucleic Acids Res 2008; 36: e44.

[85] Mattson MP, Partin J. Evidence for mitochondrial control of neuronal polarity. J Neurosci Res 1999; 56: 8-20.

[86] Trounce I, Wallace DC. Production of transmitochondrial mouse cell lines by cybrid rescue of rhodamine-6G pre-treated L-cells. Somat Cell Mol Genet 1996; 22: 81-5.

[87] Kirby DM, Rennie KJ, Smulders-Srinivasan TK, Acin-Perez R, Whittington M, Enriquez JA, et al. Transmitochondrial embryonic stem cells containing pathogenic mtDNA mutations are compromised in neuronal differentiation. Cell Prolif 2009; 42: 41324.

[88] Vayssiere JL, Cordeau-Lossouarn L, Larcher JC, Basseville M, Gros F, Croizat B. Participation of the mitochondrial genome in the differentiation of neuroblastoma cells. In Vitro Cell Dev Biol 1992; 28A: 763-72.

[89] Martin DP, Schmidt RE, DiStefano PS, Lowry OH, Carter JG, Johnson EM, Jr. Inhibitors of protein synthesis and RNA synthesis prevent neuronal death caused by nerve growth factor deprivation. J Cell Biol 1988; 106: 829-44.

[90] Gordon RY, Mugantseva EA, Khutzian SS, Podolski IY. Cycloheximide-induced inhibition of protein synthesis in hippocampal pyramidal neurons is time-dependent: differences between CA1 and CA3 areas. Neurosci Lett 2009; 461: 249-51.

[91] Morris RL, Hollenbeck PJ. Axonal transport of mitochondria along microtubules and Factin in living vertebrate neurons. J Cell Biol 1995; 131: 1315-26.

[92] Ligon LA, Steward O. Role of microtubules and actin filaments in the movement of mitochondria in the axons and dendrites of cultured hippocampal neurons. J Comp Neurol 2000; 427: 351-61.

[93] Mironov SL, Ivannikov MV, Johansson M. $\left[\mathrm{Ca}^{2+}\right]_{\mathrm{i}}$ signaling between mitochondria and endoplasmic reticulum in neurons is regulated by microtubules. From mitochondrial permeability transition pore to $\mathrm{Ca}^{2+}$-induced $\mathrm{Ca}^{2+}$ release. J Biol Chem 2005; 280: 715-21. 
[94] Mironov SL. Spontaneous and evoked neuronal activities regulate movements of single neuronal mitochondria. Synapse 2006; 59: 403-11.

[95] Song W, Bossy B, Martin OJ, Hicks A, Lubitz S, Knott AB, et al. Assessing mitochondrial morphology and dynamics using fluorescence wide-field microscopy and 3D image processing. Methods 2008; 46: 295-303.

[96] Uo T, Dworzak J, Kinoshita C, Inman DM, Kinoshita Y, Horner PJ, et al. Drp1 levels constitutively regulate mitochondrial dynamics and cell survival in cortical neurons. Exp Neurol 2009; 218: 274-85.

[97] Bauer MF, Neupert W. Import of proteins into mitochondria: a novel pathomechanism for progressive neurodegeneration. J Inherit Metab Dis 2001; 24: 166-80.

[98] Guo Y, Cheong N, Zhang Z, De Rose R, Deng Y, Farber SA, et al. Tim50, a component of the mitochondrial translocator, regulates mitochondrial integrity and cell death. $\mathrm{J}$ Biol Chem 2004; 279: 24813-25.

[99] Chang DT, Honick AS, Reynolds IJ. Mitochondrial trafficking to synapses in cultured primary cortical neurons. J Neurosci 2006; 26: 7035-45.

[100] Armstrong JS. Mitochondrial medicine: pharmacological targeting of mitochondria in disease. Br J Pharmacol 2007; 151: 1154-65.

[101] Szewczyk A, Wojtczak L. Mitochondria as a pharmacological target. Pharmacol Rev 2002; 54: 101-27.

[102] Kyriakouli DS, Boesch P, Taylor RW, Lightowlers RN. Progress and prospects: gene therapy for mitochondrial DNA disease. Gene Ther 2008; 15: 1017-23.

[103] Jekabsons MB, Nicholls DG. Bioenergetic analysis of cerebellar granule neurons undergoing apoptosis by potassium/serum deprivation. Cell Death Differ 2006; 13: 1595 610.

[104] Oliveira JM, Jekabsons MB, Chen S, Lin A, Rego AC, Goncalves J, et al. Mitochondrial dysfunction in Huntington's disease: the bioenergetics of isolated and in situ mitochondria from transgenic mice. J Neurochem 2007; 101: 241-9.

[105] Gerencser AA, Neilson A, Choi SW, Edman U, Yadava N, Oh RJ, et al. Quantitative Microplate-Based Respirometry with Correction for Oxygen Diffusion. Anal Chem 2009; 81: 6868-6878.

[106] Choi SW, Gerencser AA, Nicholls DG. Bioenergetic analysis of isolated cerebrocortical nerve terminals on a microgram scale: spare respiratory capacity and stochastic mitochondrial failure. J Neurochem 2009; 109: 1179-91.

[107] Nicholls DG, Johnson-Cadwell L, Vesce S, Jekabsons M, Yadava N. Bioenergetics of mitochondria in cultured neurons and their role in glutamate excitotoxicity. J Neurosci Res 2007; 85: 3206-12.

[108] Nicholls DG. Spare respiratory capacity, oxidative stress and excitotoxicity. Biochem Soc Trans 2009; 37: 1385-8.

[109] Yadava N, Nicholls DG. Spare respiratory capacity rather than oxidative stress regulates glutamate excitotoxicity after partial respiratory inhibition of mitochondrial complex I with rotenone. J Neurosci 2007; 27: 7310-7.

[110] Brand MD. The proton leak across the mitochondrial inner membrane. Biochim Biophys Acta 1990; 1018: 128-33.

[111] Amo T, Brand MD. Were inefficient mitochondrial haplogroups selected during migrations of modern humans? A test using modular kinetic analysis of coupling in mitochondria from cybrid cell lines. Biochem J 2007; 404: 345-51.

[112] Allen NJ, Karadottir R, Attwell D. A preferential role for glycolysis in preventing the anoxic depolarization of rat hippocampal area CA1 pyramidal cells. J Neurosci 2005; 25: 848-59. 
[113] Ahmed SM, Rzigalinski BA, Willoughby KA, Sitterding HA, Ellis EF. Stretch-induced injury alters mitochondrial membrane potential and cellular ATP in cultured astrocytes and neurons. J Neurochem 2000; 74: 1951-60.

[114] Reinhardt R, Manaenko A, Guenther A, Franke H, Dickel T, Garcia de Arriba S, et al. Early biochemical and histological alterations in rat corticoencephalic cell cultures following metabolic damage and treatment with modulators of mitochondrial ATPsensitive potassium channels. Neurochem Int 2003; 43: 563-71.

[115] Torrecilla A, Marques AF, Buscalioni RD, Oliveira JM, Teixeira NA, Atencia EA, et al. Metabolic fate of AMP, IMP, GMP and XMP in the cytosol of rat brain: an experimental and theoretical analysis. J Neurochem 2001; 76: 1291-307.

[116] Iijima T, Mishima T, Tohyama M, Akagawa K, Iwao Y. Mitochondrial membrane potential and intracellular ATP content after transient experimental ischemia in the cultured hippocampal neuron. Neurochem Int 2003; 43: 263-9.

[117] Leyssens A, Nowicky AV, Patterson L, Crompton M, Duchen MR. The relationship between mitochondrial state, ATP hydrolysis, $\left[\mathrm{Mg}^{2+}\right]_{\mathrm{i}}$ and $\left[\mathrm{Ca}^{2+}\right]_{\mathrm{i}}$ studied in isolated rat cardiomyocytes. J Physiol 1996; 496: 111-28.

[118] Abramov AY, Scorziello A, Duchen MR. Three distinct mechanisms generate oxygen free radicals in neurons and contribute to cell death during anoxia and reoxygenation. $\mathbf{J}$ Neurosci 2007; 27: 1129-38.

[119] Imamura H, Nhat KP, Togawa H, Saito K, Iino R, Kato-Yamada Y, et al. Visualization of ATP levels inside single living cells with fluorescence resonance energy transfer-based genetically encoded indicators. Proc Natl Acad Sci USA 2009; 106: 15651-6.

[120] Berg J, Hung YP, Yellen G. A genetically encoded fluorescent reporter of ATP:ADP ratio. Nat Methods 2009; 6: 161-6.

[121] Gajewski CD, Yang L, Schon EA, Manfredi G. New insights into the bioenergetics of mitochondrial disorders using intracellular ATP reporters. Mol Biol Cell. 2003; 14: 362835.

[122] Ward MW, Rego AC, Frenguelli BG, Nicholls DG. Mitochondrial membrane potential and glutamate excitotoxicity in cultured cerebellar granule cells. J Neurosci 2000; 20: 7208-19.

[123] Duchen MR. Mitochondria in health and disease: perspectives on a new mitochondrial biology. Mol Aspects Med 2004; 25: 365-451.

[124] Duchen MR. $\mathrm{Ca}(2+)$-dependent changes in the mitochondrial energetics in single dissociated mouse sensory neurons. Biochem J 1992; 283: 41-50.

[125] Vergun O, Keelan J, Khodorov BI, Duchen MR. Glutamate-induced mitochondrial depolarisation and perturbation of calcium homeostasis in cultured rat hippocampal neurones. J Physiol 1999; 519: 451-66.

[126] Oliveira JM, Goncalves J. In situ mitochondrial $\mathrm{Ca}^{2+}$ buffering differences of intact neurons and astrocytes from cortex and striatum. J Biol Chem 2009; 284: 5010-20.

[127] Nicholls DG, Vesce S, Kirk L, Chalmers S. Interactions between mitochondrial bioenergetics and cytoplasmic calcium in cultured cerebellar granule cells. Cell Calcium 2003; 34: 407-24.

[128] Vesce S, Jekabsons MB, Johnson-Cadwell LI, Nicholls DG. Acute glutathione depletion restricts mitochondrial ATP export in cerebellar granule neurons. J Biol Chem 2005; 280: 38720-8.

[129] Bernardi P, Scorrano L, Colonna R, Petronilli V, Di Lisa F. Mitochondria and cell death. Mechanistic aspects and methodological issues. Eur J Biochem 1999; 264: 687-701.

[130] Chalmers S, Nicholls DG. The relationship between free and total calcium concentrations in the matrix of liver and brain mitochondria. J Biol Chem 2003; 278: 19062-70. 
[131] Filippin L, Abad MC, Gastaldello S, Magalhaes PJ, Sandona D, Pozzan T. Improved strategies for the delivery of GFP-based $\mathrm{Ca} 2+$ sensors into the mitochondrial matrix. Cell Calcium 2005; 37: 129-36.

[132] Pozzan T, Rudolf R. Measurements of mitochondrial calcium in vivo. Biochim Biophys Acta 2009; 1787: 1317-23.

[133] Brocard JB, Tassetto M, Reynolds IJ. Quantitative evaluation of mitochondrial calcium content in rat cortical neurones following a glutamate stimulus. J Physiol 2001; 531: 793 805.

[134] Gillessen T, Grasshoff C, Szinicz L. Mitochondrial permeability transition can be directly monitored in living neurons. Biomed Pharmacother 2002; 56: 186-93.

[135] Petronilli V, Miotto G, Canton M, Brini M, Colonna R, Bernardi P, et al. Transient and long-lasting openings of the mitochondrial permeability transition pore can be monitored directly in intact cells by changes in mitochondrial calcein fluorescence. Biophys J 1999; 76: 725-34.

[136] Vergun O, Votyakova TV, Reynolds IJ. Spontaneous changes in mitochondrial membrane potential in single isolated brain mitochondria. Biophys J 2003; 85: 3358-66.

[137] Elmore SP, Nishimura Y, Qian T, Herman B, Lemasters JJ. Discrimination of depolarized from polarized mitochondria by confocal fluorescence resonance energy transfer. Arch Biochem Biophys 2004; 422: 145-52.

[138] Edwards JL, Quattrini A, Lentz SI, Figueroa-Romero C, Cerri F, Backus C, et al. Diabetes regulates mitochondrial biogenesis and fission in mouse neurons. Diabetologia 2009; 53: 160-9.

[139] Lentz SI, Edwards JL, Backus C, McLean LL, Haines KM, Feldman EL. Mitochondrial DNA (mtDNA) Biogenesis: Visualization and Duel Incorporation of BrdU and EdU Into Newly Synthesized mtDNA In Vitro. J Histochem Cytochem 2010; 58: 207-18.

[140] Rui Y, Tiwari P, Xie Z, Zheng JQ. Acute impairment of mitochondrial trafficking by beta-amyloid peptides in hippocampal neurons. J Neurosci 2006; 26: 10480-7.

[141] Rizzuto R, Brini M, Pizzo P, Murgia M, Pozzan T. Chimeric green fluorescent protein as a tool for visualizing subcellular organelles in living cells. Curr Biol 1995; 5: 635-42.

[142] Twig G, Graf SA, Wikstrom JD, Mohamed H, Haigh SE, Elorza A, et al. Tagging and tracking individual networks within a complex mitochondrial web with photoactivatable GFP. Am J Physiol Cell Physiol 2006; 291: C176-84.

[143] Buckman JF, Hernandez H, Kress GJ, Votyakova TV, Pal S, Reynolds IJ. MitoTracker labeling in primary neuronal and astrocytic cultures: influence of mitochondrial membrane potential and oxidants. J Neurosci Methods 2001; 104: 165-76.

[144] Gerencser AA, Nicholls DG. Measurement of instantaneous velocity vectors of organelle transport: mitochondrial transport and bioenergetics in hippocampal neurons. Biophys J 2008; 95: 3079-99.

[145] Trushina E, Dyer RB, Badger JD, 2nd, Ure D, Eide L, Tran DD, et al. Mutant huntingtin impairs axonal trafficking in mammalian neurons in vivo and in vitro. Mol Cell Biol 2004; 24: 8195-209.

[146] Orr AL, Li S, Wang CE, Li H, Wang J, Rong J, et al. N-terminal mutant huntingtin associates with mitochondria and impairs mitochondrial trafficking. J Neurosci 2008; 28: 2783-92.

[147] Wang X, Su B, Siedlak SL, Moreira PI, Fujioka H, Wang Y, et al. Amyloid-beta overproduction causes abnormal mitochondrial dynamics via differential modulation of mitochondrial fission/fusion proteins. Proc Natl Acad Sci USA 2008; 105: 19318-23.

[148] Chance B, Schoener B, Oshino R, Itshak F, Nakase Y. Oxidation-reduction ratio studies of mitochondria in freeze-trapped samples. NADH and flavoprotein fluorescence signals. $\mathrm{J}$ Biol Chem 1979; 254: 4764-71. 
[149] Schuchmann S, Kovacs R, Kann O, Heinemann U, Buchheim K. Monitoring NAD(P)H autofluorescence to assess mitochondrial metabolic functions in rat hippocampalentorhinal cortex slices. Brain Res Brain Res Protoc 2001; 7: 267-76.

[150] Polster BM, Fiskum G. Mitochondrial mechanisms of neural cell apoptosis. J Neurochem 2004; 90: 1281-9.

[151] Reeve AK, Krishnan KJ, Elson JL, Morris CM, Bender A, Lightowlers RN, et al. Nature of mitochondrial DNA deletions in substantia nigra neurons. Am J Hum Genet 2008; 82: 228-35.

[152] Kraytsberg Y, Bodyak N, Myerow S, Nicholas A, Ebralidze K, Khrapko K. Quantitative analysis of somatic mitochondrial DNA mutations by single-cell singlemolecule PCR. Methods Mol Biol 2009; 554: 329-69. 


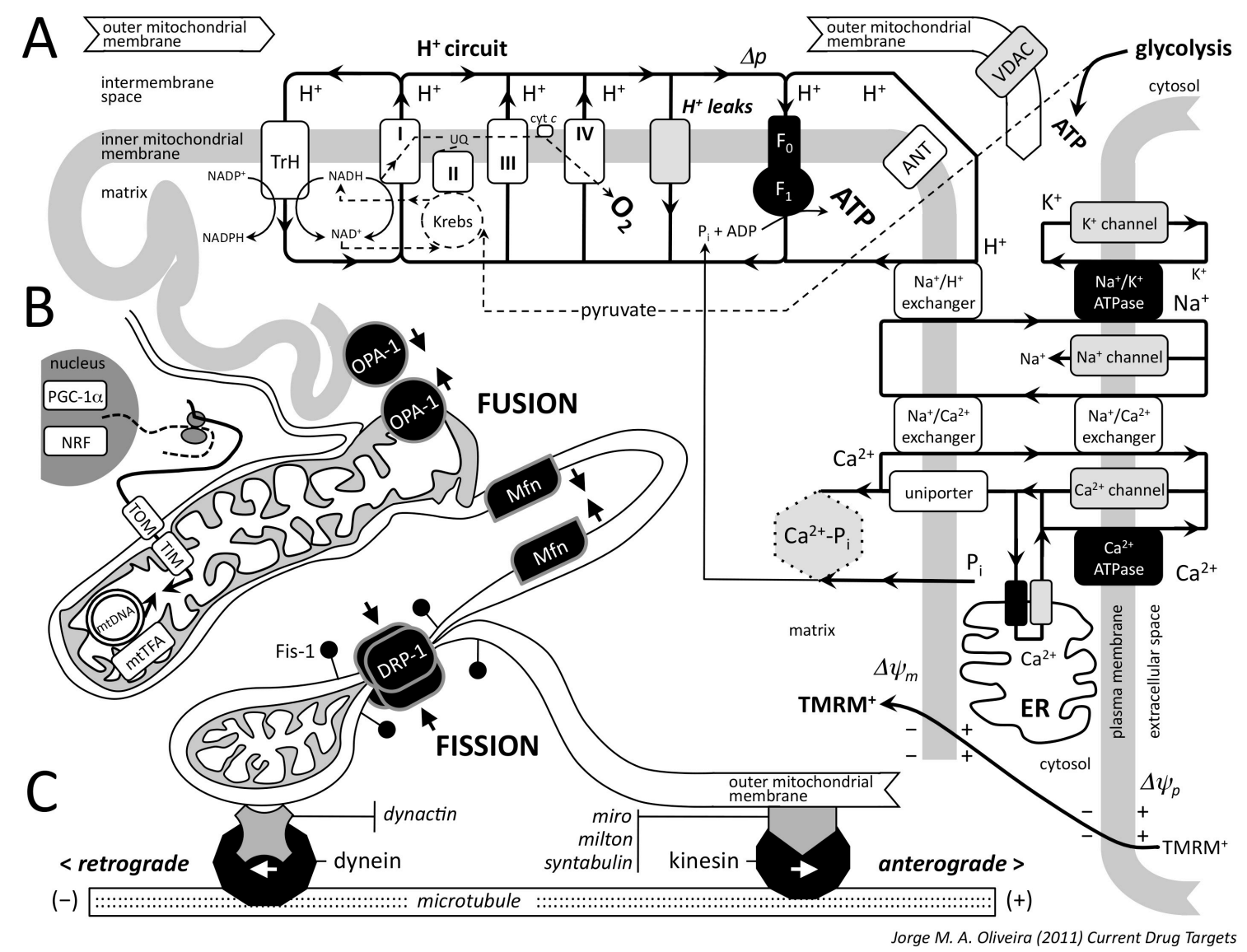

Figure 1. Mitochondrial bioenergetics and dynamics.

$\boldsymbol{A}$-(left to right), Respiratory chain and proton circuit. Transhydrogenase (TrH), complexes (IIV), ubiquinone (UQ) and cytochrome $c$ (cyt $c$ ), $\mathrm{H}^{+}$leaks and $\mathrm{F}_{0} \mathrm{~F}_{1}$ ATPase generating ATP. Adenine nucleotide translocase (ANT) and voltage dependent anion channel (VDAC), at the inner (grey) and outer (white) mitochondrial membranes, respectively. Glycolysis (top right) feeds mitochondria via pyruvate (dashed lines).

A-(top-right to bottom), Simplified circuits for $\mathrm{Ca}^{2+}$ and other ions across mitochondrial, endoplasmic reticulum (ER) and plasma membranes. Grey hexagon depicts calcium phosphate complexes $\left(\mathrm{Ca}^{2+}-\mathrm{P}_{\mathrm{i}}\right)$. TMRM ${ }^{+}$(bottom right) distribution influenced by $\Delta \psi_{\mathrm{m}}$ and $\Delta \psi_{\mathrm{p}}$

$\boldsymbol{B}$, Biogenesis, transcription factors and protein import via outer and inner membrane translocases (TOM and TIM). Fusion (outer and inner membranes) and fission via respective GTPases. $\boldsymbol{C}$, Bi-directional microtubule-based transport, motors and adaptor proteins. See text for further details. 